\title{
INNOVATIVE TECHNOLOGIES FOR NEW MATERIALS USING MICRO/NANO ELEMENTS
}

\author{
Dimitar Karastoyanov ${ }^{1 *}$, Rosen Petrov ${ }^{1}$, and Milena Haralampieva ${ }^{1}$ \\ ${ }^{1}$ Institute of Information and Communication Technologies (IICT), B1. 2, Ac. G. Bonchev str., 1113 Sofia, Bulgaria
}

\begin{abstract}
The paper describes innovative technologies for obtaining of new materials, alloys and coatings with very high hardness and wear resistance, using different approaches - electro less chemical nickeling; pressing and sintering the parts, coated with a fine powder; high temperature methods with Taman furnaces, building materials. The new materials, alloys and coatings contain micro and/or nano elements - carbides, nitrides, oxides.
\end{abstract}

\section{Introduction}

Extruding (pressing by pushing) of sheet material from non-metal materials (Plexiglas, PVC, other plastics) is widely used in households. Gifts, flowers, sugar and chocolate packing is made from thin aluminum sheets. Thin Plexiglas sheets are used to make pack-boxes, and thick nylon sheets are used to make bags, raincoats, etc. Renovation of the extruding shafts is done by a small number of companies at high production and transportation costs.

Silicon carbide coatings on iron powder metallurgical products are used in powder metallurgy for surface compacting and carbidization. The powder metallurgical products are heated in specialized furnaces using different gases. There are also plasma ionic methods for the surface treatment of powder metallurgical products, electron beam methods, etc.

In modern technological processes with high temperatures (over $2000{ }^{0} \mathrm{C}$ ), the so-called Tammann furnaces, are the most commonly used equipment. Tammann furnaces are used in modern processes for the production of materials in the form of powders, and the sintering of composite. Powders, produced in Tammann furnaces are carbides, tungsten, the complex titaniumtungsten carbide, chromium, tantalum and niobium, molybdenum. Produced are borides, nitrides and silicides of transition metals.

\footnotetext{
* Corresponding author: dimikara@abv.bg
}

Sustainable light nanomaterials with increased insulation properties has great application in civil engineering. Their thermal transfer is being reduced at nanometric scale. For example, the nanoinsulation materials have 3-5 times lower thermal conductivities, resulting reduced material thickness but same performance as regular insulation.

\section{State of the art}

\subsection{Electro less chemical nickel coating}

The vast amount of production of smooth sheets of various sizes from these materials has brought to the development of technologies in which the material is pressed and pushed out (extruded) between shafts of various diameters $(100-500 \mathrm{~mm})$ and various lengths $(1-3 \mathrm{~m})$. The shafts are chromed, have very narrow tolerances of diameter size and very high degree of smoothness by polishing.

With the time and at high production rate shafts age, their surface wears out, and sometimes scratches appear in incidents. All this makes the shaft surface not precisely circular and even. Because of a new shaft's very high price, renovation of the defected shaft is applied in such cases by applying a new coating and polishing it to mirror shine.

The main goal is the creation of industrially applicable technology and the design of a relevant technological line for laying of coatings with high mechanical wear- 
resistance and surface-smoothness for renovation of the working area of shafts for extruding sheet material (PVC, Plexiglas, other plastics) by laying and polishing of new types of highly wear-resistant coatings based on ultra disperse nickel coatings with, nanodispersoids and/or nano-particles included, [1]. Additional reason is the existing EU Directive for prohibition of coatings and activities using highly harmful substances.

\subsection{Silicone-carbide coatings on iron powder- metalurgical parts}

There are methods for surface cementation of sintered powder metallurgical products [2], which are heated in specialized furnaces at $840-860{ }^{\circ} \mathrm{C}$ using methane and others carbon-containing gases.

There are also known advanced plasma ionic methods for the surface treatment of powder metallurgical products, in which nitration, carbidization and boring are carried out. The products are heated in low-temperature plasma in specialized gas furnaces (nitrogen containing carbon, boron hydrides).

There are electron beam methods [3] for surface silicification, as well as the use of carbides, nitrides, borides, oxides, volatile metal chlorides.

It is known a method [4] in which powder metallurgical products are obtained by mixing iron powders with silicon carbide, then compressed, sintered and eventually calibrated.

The disadvantage of the methods is that for surface treatment of powder metallurgical products they must be pre-sintered and calibrated to meet the required dimensions.

Another disadvantage is that the methods are carried out in specialized facilities.

\subsection{High temperature technologies}

The high temperature technologies have applied research results in the following areas:

- Cheaper obtaining of micro and nano powders for various areas, including the use as modifiers in casting non-ferrous metals and composites, modified as alloys based on copper, iron, steel,

- Impregnation of articles of tungsten, molybdenum (hard caking heavy elements), as well as carbides, borides or nitrides of the transition metals of the IV, V and VI subgroups of the periodic system of elements

- Obtaining of special materials based on graphite,
- Obtaining of materials for hard, wear-resistant coatings of nano-elements for high-temperature processes.

Some of the approved technologies of the Tammann furnace are as follows [5]:

- Carbo thermal obtaining of Si-Mn-V ferro alloy,

- Electro-alumo thermal obtaining of Si-Mn-V,

- Electro-silico-alumo thermal obtaining of $\mathrm{Mn}-\mathrm{V}$,

- Preparation of Si-Mn-V alloy by heat treatment carbo,

- Preparation of si-mn-v ferro-alloy by electro-alumo thermal processing.

\section{Technical nature}

\subsection{Electro less chemical nickeling}

In IICT-BAS we have developed technology for chemical (electroless-autocatalytic) plating the working surface of the shaft (Fig. 1) for extruding a film with the inclusion of nano-particles in a matrix of nickel in order to improve the hardness and wear resistance of the coating with thickness up to $25 \mu \mathrm{m}$ at $250 \mu \mathrm{m}$ chrome plating. There have been experimental studies of $\mathrm{Al}_{2} \mathrm{O}_{3}, \mathrm{SiC}$ and nano diamonds with 4-20 nm. A suitable formulation of the solution is selected and the optimum concentrations of the components and exact ratios of time are obtained to achieve the desired coating thickness. It has been shown that in the ground of a desired smoothness steel base (which process is known and well utilized), the small chemical nickel coating incorporating nanoparticles follows the topography of the surface and minimal finishing works are necessary. Methods are developed for testing the hardness and chemical durability of nickel coatings including nanoparticles. The obtained results are protected by 21 publications in journals of national and international conferences, including 3 patent applications in Bulgaria, [6].

The proposed technology is electroless chemical nickeling. During the process at room temperature the nano elements are inserted and attached to the nickel crystal grid. This makes the coating hard and wear-resistant.

The plating of test samples was performed (Fig. 2).

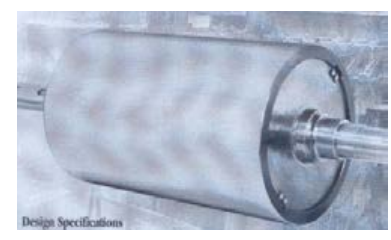

Fig. 1. Calander shaft. 
Several of the samples were used for preliminary tests for chemical staining / oxidation of nikel-phosphor coatings.

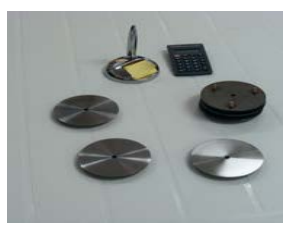

Fig. 2. Coating of samples.

\subsection{Method for obtaining silicone-carbide coatings on iron powder-metallurgical parts}

We are developing a method for the creating of silicon carbide coatings on iron powder metallurgical products where the parts are coated with a fine silicon carbide powder, then are pressed and sintered at a temperature of 900 to $1250{ }^{\circ} \mathrm{Cin}$ conventional equipment [7].

The advantage of the idea is that in the method of application of the silicon carbide coating and its sintering on the powder metallurgical products is carried out in conventional equipment, widely used in powder metallurgy.

Another advantage of the method is that the superficial (surface) silicon carbide coatings on the powder metallurgical details give higher rigidity, wear resistance and corrosion resistance.

Example 1: Carbosilication of friction wear articles (gears, hulls and parts in which the transport of containing solids liquids is carried out) is compressed from a "Hoganes Distaloy EA" powder, usually at 600MPA, to obtain after sintering at $1150-1170{ }^{\circ} \mathrm{C}$ product density above $7.1 \mathrm{~g} / \mathrm{cm}^{3}$. Regardless of the high relative density of the sintered articles and their wear resistance due to the content of nickel, copper and molybdenum in the composition of the powders used (4.0, 1.5 and $0.5 \%$ respectively), their carbosilication by silicon carbide coating with a particle size of $0.1-0.06 \mathrm{~mm}$ leads to compaction of the surface layer. The abrasion resistance of the articles due to the carbosilicized surface with a layer thickness of 0.6-0.8 mm increased sharply. The products do not need additional heat treatment.

Example 2: Powder metallurgical products are compacted from "Hoganes NC100-24" powder at a pressure of $500 \mathrm{MPA}$ and sintered at $1150 \pm 20^{\circ} \mathrm{C}$, covered with powder of silicon carbide with a particle size of 0.1-0.06 mm at a relative density of $6.75-6.8 \mathrm{~g} / \mathrm{cm}^{3}$. The carbosilicized layer reaches $1 \mathrm{~mm}$. The parts are used without additional heat treatment (cementation or nitration) in wear-resistant units.

Example 3: "Hoganes Distaloy EA + C" dustmetallurgical products, compressed at $600 \mathrm{MPA}$ and sintered at $1250{ }^{\circ} \mathrm{C}$ in a controlled $99.98 \%$ hydrogen cleaned environment, coated with fine silicon carbide with a particle size below $0.063 \mathrm{~mm}$, have the characteristics до nitro-cement products. The thickness of the carbosilicate layer is up to $0.08 \mathrm{~mm}$.

\subsection{Innovative technologies using Taman furnace}

The boron carbide occupies in the hierarchy of material hardness the third place after artificial diamonds and cubic boron nitride modification. In contrast to these two materials, the synthesis of $\mathrm{B}_{4} \mathrm{C}$ proceeds relatively easily. Technological features of the process of activated sintering the high temperature wear-resistant material out of boron carbide are innovative. Our process technology is as follows:

1. Homogenised mixture of nano-powders of the boron carbide with tungsten carbide in the presence of a liquid phase in a ball mill,

2. Vacuum drying the homogenized mixture with a vacuum dryer,

3. Lamination / mixing nano-powder with a plasticizer. A pre-heating mixing $\mathrm{Z}$ blender is used.

4. Isostatic pressing of shapes with an isostatic press.

5. Deplasticizing of the pressed handlings in a cold furnace in an atmosphere of hydrogen or inert gas (nitrogen, argon)

6. High temperature sintering in a hydrogen atmosphere at a temperature $2240-2260{ }^{\circ} \mathrm{C}$ in a Tamman furnace-Fig. 3.

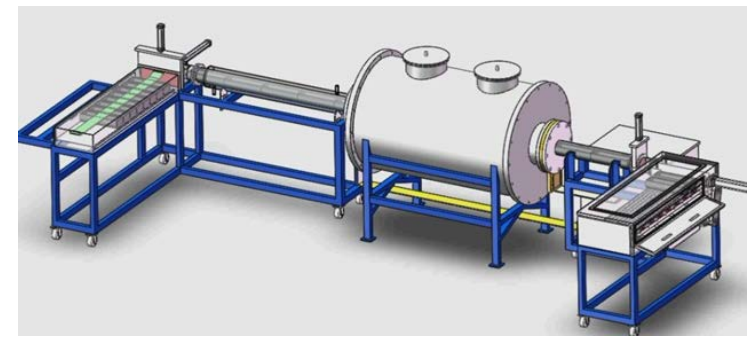

Fig. 3. Taman furnace.

For the study of the source materials (powders) as well as for the study of $3 \mathrm{D}$ internal structure of the output materials and alloys, are used the devices:

- Laser particle size analyzer ANALYSETTE 22 Nano Tec plus for the accurate measuring and dispensing of 
the concentration, size and size distribution of micro and nano particles in a mixture of materials or alloys designed for high-temperature processing.

- Industrial computerized tomography STDS-600-200/ XTH 225 for non-invasive scaning of the internal structure of a 3D objects. Examine the internal 3D structure obtained by heat treatment of metals and alloys containing micro- and nano-elements.

Examined were: Articles made from sintered boron carbide - Fig. 4; Composite material "titanium carbide - iron" - Fig.5. ;Silicon carbide on carburized iron - Fig. 6.
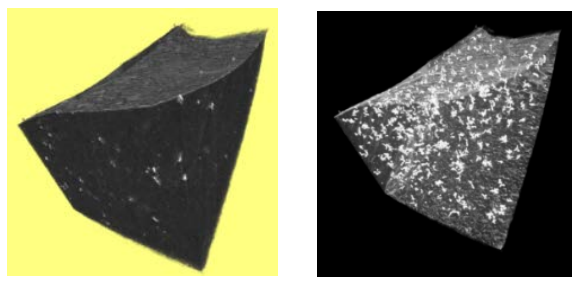

Fig 4. Flaw detection of articles of sintered boron carbide.

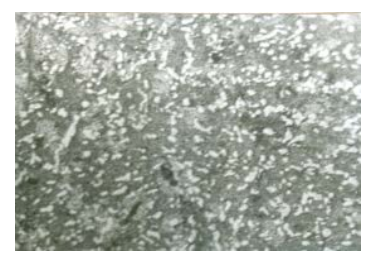

Fig.5. Microstructure of titan carbide - iron.

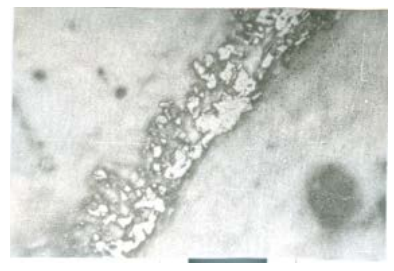

Fig.6. A layer of silico carbide on carbon iron.

\subsection{Micro/nano elements in building materials}

Example 1: Insulation materials. One of the measures which have to be taken from the design phase of every new building, in order to comply with the increased energy efficiency demands, is the thermal behavior optimization of the elements that define the building envelope. The use of the common thermal insulation materials to achieve the desired targets has some disadvantages. In most situations, it results large thickness of insulation, which can be inconvenient. Vacuum insulation panels are composite nanoinsulation materials, consisting of a nanoporous core encapsulated by an impenetrable envelope with multiple functions - Fig. 7. The panel's components can be made of different materials, having different characteristics, advantages and disadvantages. One of the products with good behaviorand which is commonly used consists of a pyrogenic silica core and multi-layered envelope. [9].

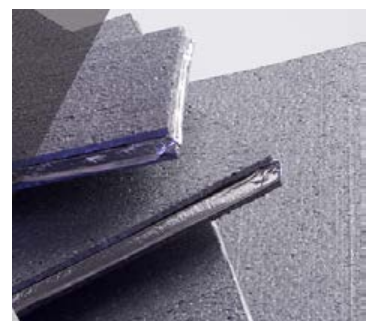

Fig. 7. Vacuum insulation panel

Example 2: Aerogel. Aerogel is a nanoinsulation material with the structure composed of spherical particles connected by thin links [10] (Fig. 8), its nanometric scale model being similar to the macroscopic one. This material is used in different domains with different purposes. In the field of building thermal insulations, the most common is the silica aerogel, which is made of a nanometric porous network of $\mathrm{SiO} 2$ links. Regarding the structure of the material, there are two different types of aerogel, which have certain application purposes. The monolithic aerogel) has a smooth surface and is used for both thermal insulations of building envelope components and glazings. The granular aerogel is a noncontinuous material which is used mostly for glazings or in different material composites.

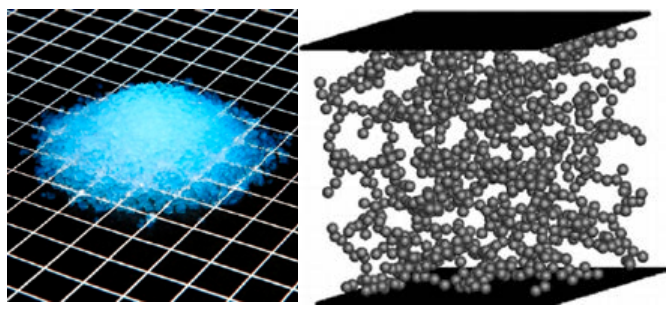

Fig. 8. Aerogel.

\section{Conclusion}

The resulting coating has improved hardness and wear resistance, and its production does not harmful pollute the environment. The production would be of interest to producers of sheet metal and non-metallic materials tinfoil, plasters, wallpaper, Plexiglas panels etc.

The process for producing silicon carbide coatings on iron powder metallurgical products is accomplished by sintering with silicon carbide powder of pressed powder 
metallurgical articles and then they are sintered at temperatures of 900 to $1250{ }^{\circ} \mathrm{C}$ whereby the resulting layer of 0.6 to $0.8 \mathrm{~mm}$ has a hardness HV10 above 450 , impact strength of 15 joules, which allow the use of powder metallurgical products under abrasion.

The high temperature methods are effective for obtaining materials and alloys with high hardness and wear resistance and still give the possibility of forming and processing in the production of industrial tools.

To improve the energy performance of buildings, materials with micro and nano elements are increasingly used worldwide. Build-in modules, such as windows, panels and more have better insulating and thermal properties.

Acknowledgments: This article is partially supported by the Bulgarian NSF Grant No KP-06-OPR01/3-2018

\section{References}

1. D. Karastoyanov, T. Penchev, M. Kandeva, Tribological Characteristics of Nano Structured Nickel Coatings for Renovating of Extruding Shafts., 2012 International Conference on Advanced Design and Manufacturing Engineering (IC ADME 2012), August 16-18 2012, Taiyuan, China., Published in International Journal "Applied Mechanics and Materials", vol 217-219, 221-225, ISBN-13: 978-3-03785-380-1 (2012)

2. D.Buckov, Research, technology, equipment, production, industrial services., Ion nitriding and carbonitrification., TU-Sofia, Sofia, pp. 3-13 (in Bulgarian) (2011)

3. Yu.F. Ternovi, V.T. Zubkova, Yu.V. Artamonov, A.B. Kuratchenko, Yu.V Melnikov, L.I. Zolotareva
Production of High Efficiency Complex Alloy Steel and Alloy with Ceramic and Intermetallic Strengthening., Metallurgical and Mining Industry, Vol.4, № 1, pp.33-39 (2012)

4. US Patent No 6,682,579 B2

5. P. Petrov, Semi-industrial production of silicomanganese vanadium ferro-alloy, Dissertation, Sofia, (in Bulgarian) (2012)

6. M. Kandeva, D. Karastoyanov, B. Ivanova, Friction and Wear of Ni Coatings with Nanosize Particles of SiC., 5th WORLD TRIBOLOGY CONGRESS WTC 2013, September 8-13, Torino, Italy, www.wtc2013.it, ISBN 978-88-908-185, pp 63-64 (2013)

7. D. Karastoyanov, N. Stoimenov, B. Popov, Method for obtaining silicone-carbide coatings on iron powder-metallurgical parts., BG Patent application, No 112715, April 3th 2018 (in Bulgarian) (2018)

8. N. Stoimenov, M. Groueva, D. Karastoyanov, B. Popov, N. Sabotinkov, Robotized High-Temperature Technology Producing Materials and Alloys for Grinding Media., 5th International Conference on Mathematics and Computers in Sciences and Industry, (MCSI 2018), Corfu Island, Greece, August 25-27, 2018, IEEE CPS Proceedings, indexed in IEEExplore, ISI, SCOPUS, EI Compendex. (2018)

9. https://ec.europa.eu/energy/en/topics/energyefficiency/energy-efficiency-directive

10. Nano insulation materials for application in nZEB 